\title{
Clinical applications of small bowel capsule endoscopy
}

This article was published in the following Dove Press journal:

Clinical and Experimental Gastroenterology

25 July 2013

Number of times this article has been viewed

\section{Uri Kopylov \\ Ernest G Seidman \\ Division of Gastroenterology, McGill University Health Center, Montreal, Quebec, Canada}

\begin{abstract}
Video capsule endoscopy has revolutionized our ability to visualize the entire small bowel mucosa. This modality is established as a valuable tool for the diagnosis of obscure gastrointestinal bleeding, Crohn's disease, small bowel tumors, and other conditions involving the small bowel mucosa. This review includes an overview of the current and potential future clinical applications of small bowel video endoscopy.
\end{abstract}

Keywords: small bowel video capsule endoscopy, obscure gastrointestinal bleeding, Crohn's disease, small bowel tumors, patency capsule

\section{Introduction}

The small bowel has largely been inaccessible for direct endoscopic examination, with only the duodenum, proximal jejunum, and terminal ileum being subject to direct visualization by a conventional endoscope. This paradigm changed dramatically with the invention and introduction of small bowel video capsule endoscopy (VCE) in 2000. ${ }^{1}$ The capsule, manufactured by Given Imaging (Yokneam, Israel) was first approved for clinical use in the US and Europe in $2001 .^{2}$ Several other manufacturers have released their own versions of this device in the following years. Currently, VCE technology is continuously gaining popularity, with tens of thousands of examinations performed annually worldwide. Over 1,000 studies pertaining to different aspects of capsule endoscopy have been published in the last decade. ${ }^{3}$ Capsule endoscopy technology is subject to constant technical improvement and additional indications for its use are emerging.

\section{Technical aspects}

Although the technical specifications may vary between the different manufacturers, the principal engineering concepts are similar. The capsule is comprised of a light source, lens, complementary metal-oxide-semiconductor (CMOS) imager, battery, and a wireless transmitter. The physical size of the Pillcam SB2 capsule (Given Imaging) is $26 \times 11 \mathrm{~mm}$. The capsule is easily ingested, and propelled by natural peristalsis from mouth to anus. In patients with swallowing difficulties and certain esophageal pathologies (such as Zenker's diverticulum) the capsule insertion can be facilitated by "front loading" on an endoscope. The battery is usually sufficient for 8-12 hours of video recording and transmission. The cecum is not reached by the end of the battery life in $8 \%-40 \%$ of the examinations. ${ }^{4-7}$ However, in the vast majority of cases, the capsule is spontaneously excreted by the patients.
Correspondence: Uri Kopylov IBD Center, Montreal General Hospital, CI 0.145, 1650 Cedar Avenue, Montreal, QC, Canada, H3G IA4

$\mathrm{Tel}+\mathrm{I} 5$ I4 3779356

Email ukopylov@gmail.com 
The capsule takes images at the speed of two frames per second, with a $156^{\circ}$ angle of view (SB2 capsule, Given Imaging) and automatic light control. The images are wirelessly transmitted to the recording device that is worn by the patient, usually on a belt. The images are downloaded as a continuous film to a computer workstation equipped with specialized software that incorporates multiple technological enhancements aimed at enhancing diagnostic accuracy and shortening the review time. These include a localization system, a blood detector, a double- and quadric-picture viewer, a quick viewer, color enhancement system, inflammation (Lewis) scoring system, and an atlas of common findings. ${ }^{8}$

\section{Preparation for capsule endoscopy}

The preparation for VCE suggested by manufacturers of capsule endoscopy systems consists only of a clear liquid diet the day prior to the exam, and an overnight (8-12 hour) fast. Several studies over the past decade have evaluated the impact of a bowel preparation using different protocols for increasing the cleanliness, and improving the diagnostic efficacy and rates of completion of the examination. ${ }^{9-17}$ A recent meta-analysis examined the value of bowel preparation prior to VCE. ${ }^{18}$ This included twelve retrospective and prospective studies comparing 718 patients who received polyethylene glycol or sodium phosphate using different regimens and 444 patients receiving clear fluid diet without a bowel preparation. The data demonstrated that bowel preparation had a significant impact on diagnostic yield (odds ratio [OR] $-1.813,95 \%$ confidence interval [CI] 1.251-2.628, $P=0.002)$ and small bowel visualization quality (OR $-2.113,95 \%$ CI $1.252-3.566, P=0.005)$, but not on completion rate or transit times. ${ }^{18}$ However, bowel preparation poses a significant inconvenience for the patient, and thus renders the procedure less "user-friendly." Moreover, the clinical significance of the slight increase in the diagnostic accuracy achieved by a tedious bowel preparation is unclear.

\section{Main clinical indications for performance of VCE}

The major clinical indications for VCE are: ${ }^{19}$ evaluation of occult or obscure gastrointestinal bleeding, suspected Crohn's disease (CD), suspected small bowel tumor, surveillance of inherited polyposis syndromes, evaluation of partially responsive/refractory celiac disease, and evaluation of protein losing-enteropathy. The diagnostic yield of VCE for selected clinical indications is described in Table 1.
Table I Diagnostic yield of video capsule endoscopy for selected clinical indications

\begin{tabular}{ll}
\hline Indication & Yield \\
\hline Obscure gastrointestinal bleeding & $35 \%-73 \%^{107-110}$ \\
Suspected small bowel Crohn's disease & $50 \%-71 \%^{45}$ \\
Suspected small bowel tumor & $4 \%-8.9 \%^{61,111,112}$ \\
Iron deficiency anemia without overt & $25.7 \%-45 \%^{\prime \prime \prime}$ \\
gastrointestinal bleeding & \\
Abdominal pain & $6 \%{ }^{112}$ \\
Diarrhea & $14 \%^{112}$ \\
\hline
\end{tabular}

\section{Occult gastrointestinal bleeding (OGIB)}

VCE has a proven and established diagnostic yield in the evaluation of patients with obscure and OGIB with nonexplanatory gastroduodenoscopy and ileocolonoscopy ${ }^{20}$ Multiple studies comparing the diagnostic yield of VCE to that of other modalities have been published. VCE has been repeatedly proven to be superior to push enteroscopy (PE) for establishing the etiology of OGIB. ${ }^{21-24} \mathrm{~A}$ meta-analysis of 14 studies in patients with OGIB reported yields of $63 \%$ for VCE and $28 \%$ for PE. ${ }^{25}$ A meta-analysis of eleven studies comparing VCE and double balloon enteroscopy has demonstrated a similar diagnostic accuracy for most indications, including evaluation of OGIB. ${ }^{26}$ Due to its excellent safety profile and tolerability, VCE should be the procedure of choice after negative upper and lower endoscopy, and enteroscopy should usually be reserved for interventional purposes or investigation of patients with nondiagnostic VCE results. VCE was also compared to crosssectional imaging in several studies and was demonstrated to be superior to both small bowel follow through and computed tomography (CT) enteroclysis. ${ }^{25,27-29}$ In patients with OGIB and negative VCE, the rebleeding rate was low, making it reasonable to take an expectant approach with these patients, thus avoiding the need for unnecessary additional investigations. ${ }^{30}$ However, a second capsule endoscopy may lead to a diagnosis in up to $30 \%-62.5 \%$ of patients with negative initial workup and negative first $\mathrm{VCE}{ }^{31,32}$

The most common small bowel findings demonstrated in patients with OGIB are angiodysplasias $(50 \%)$, ulcers (26.8\%), and neoplastic lesions $(8.8 \%) .{ }^{33}$ Proximity of performance of VCE to the bleeding episode increases the diagnostic yield. ${ }^{34}$

\section{Crohn's disease}

The diagnosis of $\mathrm{CD}$ is based on a constellation of findings, including history and physical examination, endoscopic and radiological features, as well as laboratory and pathology findings. ${ }^{35} \mathrm{VCE}$ has important potential roles in the 
diagnosis of inflammatory bowel disease (IBD). CD involves the small bowel in $75 \%$ of the patients, and in $30 \%$ of cases the disease is exclusive to the small bowel. ${ }^{36}$ In addition, IBD restricted to the colon that cannot be characterized as either ulcerative colitis or CD (IBD unclassified [IBDU]) occurs in up to $15 \%$ of patients. The diagnosis is subject to change from ulcerative colitis/IBDU to $\mathrm{CD}$ in up to $13 \%$ of patients. ${ }^{7,37}$ This distinction may have an important clinical impact as it may influence the choice of therapy for the patient, and more importantly, guide surgical decisions.

Although VCE is most frequently used for the diagnosis of $\mathrm{CD}$, it could be utilized for monitoring the disease and for the diagnosis of complications. The most common clinical situations requiring capsule endoscopy for diagnosis and management of CD include the following: patients with a high clinical probability of $\mathrm{CD}$ and nondiagnostic colonoscopy, patients with colonoscopy findings that can be consistent with both CD and ulcerative colitis (IBDU), patients with known colonic $\mathrm{CD}$ and who present with a suspected flare-up, based on clinical or laboratory features, with a nonexplanatory colonoscopy. ${ }^{19}$

Findings associated with CD on VCE include ulcerations, erythema, mucosal edema, loss of villi, stricture, mucosal fissures, and rarely, a suspected fistula opening. ${ }^{7} \mathrm{VCE}$ for diagnosis of $\mathrm{CD}$ should be reserved for patients with high clinical index of suspicion, due to its limited specificity. Minor small bowel lesions may be present in up to $10 \%$ of normal subjects. ${ }^{38}$ The most common mimicker of CD in the small bowel is nonsteroidal anti-inflammatory medication (NSAID) induced enteropathy that may cause lesions virtually indistinguishable from those of CD. Such lesions can be demonstrated in $70 \%$ of chronic NSAID users, and are frequently demonstrated even after 2 weeks of NSAID use. ${ }^{39,40}$ Patients who are candidates for VCE should be instructed to avoid NSAIDs for at least 1 month before the examination. Small bowel mucosal lesions may result from a multitude of other pathologies, such as lymphoma, radiation enteritis, human immunodeficiency virus with opportunistic infection, intestinal tuberculosis, and Behcets disease. ${ }^{38}$ Importantly, as histological diagnosis is not feasible using VCE, it cannot confirm the etiology of the observed lesions.

The criteria for diagnosis of CD on VCE have not been well established. The most commonly used validated diagnostic score is the Lewis score. ${ }^{41}$ This score divides the small bowel into three tertiles (dividing the small bowel transit time in three) and uses an algorithm that assigns points to various findings (mucosal edema, ulcers, stricture) possibly associated with $\mathrm{CD}$ in each of the tertiles, taking in to account the severity and the reproducibility of each finding. The final score represents the number of points accumulated by the most significantly involved tertile. The Lewis score is incorporated in the software used for decoding, reading, and interpreting VCE images obtained by PillCAM (RAPID, Given Imaging). A score $<135$ is designated as normal or clinically insignificant mucosal inflammatory changes, a score between 135 and 790 indicates mild inflammation, and a score $\geq 790$ indicates moderate to severe inflammation. An additional score named the Capsule Endoscopy Crohn's Disease Activity Index (CECDAI or Niv score), was recently published. ${ }^{42}$ This score incorporates three main characteristics of CD: inflammation, extent of disease, and stricture in both the proximal and distal segments of the small bowel. It should be noted that while these scores attempt to quantify the severity and extent of small bowel CD, the lesions are not pathognomonic and may represent other causes of "enteritis."

The yield of VCE for diagnosis of CD was compared to that of cross-sectional imaging in multiple studies. Importantly, patients with suspected small bowel stenosis were excluded from these studies. The superiority of VCE over small bowel follow through and enteroclysis has been repeatedly demonstrated. ${ }^{27,28,43,44}$

For comparison with CT enterography (CTE), a recent meta-analysis demonstrated an incremental diagnostic yield (IY) of VCE in both suspected and established CD patients (IY 47\%, 95\% CI 31\%-63\%, $P<0.00001$ and IY 32\%, 95\% CI $16 \%-47 \%, P<0.0001$, respectively). ${ }^{45}$

A prospective trial ${ }^{46}$ evaluated the diagnostic accuracy of VCE, magnetic resonance enterography (MRE), and CTE in 93 patients with suspected CD as compared to ileocolonoscopy. The sensitivity and specificity for diagnosis of CD of the terminal ileum was $100 \%$ and $91 \%$ by CE, $81 \%$ and $86 \%$ by MRE, and $76 \%$ and $85 \%$ by CTE, respectively. There was a statistical difference in sensitivity when compared with CTE (VCE was more accurate then CT), but only a trend in comparison with MRE. Specificity was not significantly different between the modalities. Proximal small bowel CD was detected in 18 patients by using $\mathrm{CE}$, compared with two and six patients by using MRE or CTE, respectively $(P<0.05) .{ }^{46}$ In earlier studies, no significant differences between the diagnostic yield of VCE and MRE were detected. Overall, VCE was more accurate in diagnosing small bowel lesions and MRE was more accurate in diagnosing extra-intestinal manifestations. ${ }^{45,47,48}$ The identification of proximal small bowel CD has recently been demonstrated to be a significant negative prognostic factor for development of complicated disease, ${ }^{49}$ suggesting that VCE is advantageous in the evaluation of cases. 
VCE can also be used for monitoring ileal recurrence in $\mathrm{CD}$ patients following bowel resection and ileocolonic anastomosis. In one study, $\mathrm{CE}$ detected CD recurrence in 15 (62\%) patients, whereas ileocolonoscopy detected inflammatory lesions in the neoterminal ileum in only six (25\%) patients. ${ }^{50}$ VCE was also evaluated for a potential role in the assessment of mucosal healing after drug therapy in $\mathrm{CD} .{ }^{51}$

\section{Refractory or obscure celiac disease}

VCE is capable of capturing the fine details of the appearance of small bowel mucosa characteristic of celiac disease, such as a loss of folds, nodularity, scalloping, and a mosaic mucosal pattern. Although gastroduodenoscopy with duodenal biopsies is the current gold standard diagnostic modality, VCE can provide a safe and accurate diagnostic alternative. A recent meta-analysis compiling data from six studies demonstrated an overall pooled VCE sensitivity of 89\% (95\% CI 82\%-94\%) and specificity of $95 \%$ (95\% CI 89\%-98\%), with area under the weighted symmetric summary receiving operating characteristic (ROC) of 0.9584 when compared to duodenoscopy with biopsies. ${ }^{52}$ Experience in reading VCE had a significant impact on the detection of diagnostic findings. ${ }^{53}$ Additional techniques for advanced image analysis such as a quantitative interpretation of the variability in image brightness and texture and motility patterns have been reported to be accurate in diagnosis of celiac disease in small studies..$^{54,55}$

VCE can also be very useful in monitoring complications of celiac disease such as ulcerative jejunoileitis and small bowel tumors. ${ }^{56-58}$ These complications should be considered in refractory celiac patients who fail to improve clinically despite adherence to gluten-free diet, or who develop alarming symptoms such as progressive anemia, weight loss, or gastrointestinal bleeding. Interestingly, although celiac disease is traditionally considered an "upper small bowel" disease, the VCE findings extended into the jejunum in $45 \%$ of patients, and in some involved the entire small bowel. ${ }^{59}$ The clinical significance of such extensive small bowel disease is unclear, however these patients tended to have more severe symptoms. ${ }^{59}$

\section{Small bowel tumors}

Introduction of VCE had a major impact on detection of small bowel tumors, almost tripling their detection rate. ${ }^{19}$ Most of these tumors are discovered on examinations performed for OGIB, and at least a half of them are malignant. ${ }^{60,61}$ Interestingly, the patients diagnosed with small bowel tumors had close to five negative examinations (small-bowel followthrough, gastroduodenoscopy, colonoscopy, CT, etc) before detection of the source of OGIB as a tumor on VCE. ${ }^{60}$ Recently, a novel VCE index aimed at discrimination of small bowel tumors from benign bulges was published. ${ }^{62}$

\section{Other indications}

VCE has also been utilized for several less frequent indications. VCE was evaluated for surveillance of small bowel polyps in patients with familial polyposis syndromes such as PeutzJeghers syndrome and familial adenomatous polyposis. ${ }^{63-68}$ VCE was very sensitive for detection of small bowel polyps. These syndromes may be associated with multiple polyps that are not feasible for complete removal. Thus, the main diagnostic objective is identification of polyps with high malignant potential. This objective is not currently achievable with VCE due to an inability to perform tissue diagnosis. Clearly, a validated set of criteria for definition of the clinical significance of the polyp will be required before this modality will have routine clinical use in polyposis syndromes.

VCE was also evaluated for the investigation of chronic unexplained abdominal pain ${ }^{69}$ and irritable bowel syndrome. ${ }^{70}$ VCE is useful in such cases to demonstrate the absence of any significant findings in such patients.

Another disorder where VCE is particularly useful is in the evaluation of patients with unexplained malabsorption or protein-losing enteropathies. In our experience, VCE is excellent to detect intestinal lymphangiectasia ${ }^{71}$ and eosinophilic enteritis. $^{72}$

Importantly, data obtained by capsule endoscopy can complement and facilitate other diagnostic modalities. For example, capsule transit time can guide the decision on the initial route (antegrade versus retrograde) for therapeutic double balloon endoscopy. ${ }^{73}$ Continued progress in endoscopic techniques and VCE technology may change the diagnostic indications for both modalities in the future and increase the diagnostic benefit derived from their complementary utilization.

\section{Motility}

VCE presents an interesting and currently underexplored modality for evaluation of intestinal motility. Computerized analysis of endoluminal images with identification and quantification of contractility patterns and endoluminal motion was effective in the characterization of bowel motility disorders, ${ }^{74}$ and was also utilized for diagnosis of celiac disease. ${ }^{54} \mathrm{~A}$ motility capsule that includes $\mathrm{pH}$, temperature, and pressure sensors instead of a camera is approved by the US Food and Drug Administration for gastric transit and characterization of constipation. ${ }^{75}$ 


\section{Contraindications and risks}

The main complication of CE is capsule retention, defined as a failure to excrete the capsule for 2 weeks or more requiring directed medical, endoscopic, or surgical intervention. ${ }^{76} \mathrm{CE}$ is contraindicated in patients with known bowel strictures or swallowing disorders, and history of bowel obstruction. Recent abdominal surgery is a relative contraindication, ${ }^{19}$ along with a history of abdominal imaging or small bowel CD showing obstruction. In patients with obstructive symptoms or one of the aforementioned risk factors, cross-sectional imaging should be performed before VCE, however, absence of strictures on cross-sectional imaging does not preclude capsule retention..$^{77}$ The rate of capsule retention depends on the indication for performance of VCE: $:^{78} 0 \%$ in healthy controls, ${ }^{79} 1.4 \%$ in obscure gastrointestinal bleeding, $, 53,80,81$ $1.48 \%$ in suspected $\mathrm{CD}^{82-84} 5 \%-13 \%$ in known $\mathrm{CD},{ }^{85,86}$ and $21 \%$ in suspected small bowel obstruction. ${ }^{87}$ Importantly, slow transit of the capsule, with delayed excretion of the capsule is very common, and seen in up to $20 \%$ of the cases. ${ }^{19}$ A case of endoscopic capsule extraction after 2.5 years has been described ${ }^{88} \mathrm{~A}$ retained capsule is usually asymptomatic $^{89}$ but may be associated with symptoms of partial or complete bowel obstruction. Only six cases of bowel perforation have been reported. ${ }^{19,90}$ Usually, the retained capsule can be extracted with surgery or enteroscopy. If the cause is an inflammatory stricture, corticosteroids have been useful in some cases. No consensus on the timing of intervention exists, and it is unclear how long one should wait before intervention in asymptomatic patients. An important safety measure aimed at minimizing the chance of capsule retention in high risk patients is the prior use of a patency capsule (see below). The patients should be informed that the risk of retention and subsequent surgery exists, occurring in $0.75 \%$ of patients overall. ${ }^{20}$

A theoretical risk of electromagnetic interference exists in patients with cardiac pacemakers and implanted cardioverters (ICD). However, in several studies no interferences with the pacing activity were demonstrated, and in rare cases an interference with telemetry tracing or interference with image quality of the VCE recording was demonstrated. ${ }^{91-93}$ However, it is recommended to consult a cardiologist/pacemaker clinic before performance of VCE in a patient with a pacemaker/ICD ${ }^{94}$ Pregnancy is considered to be a contraindication to VCE due to a lack of safety data. ${ }^{95}$

\section{Patency capsule}

The patency capsule has the same shape and dimensions as the real video capsule. It is comprised of a dissolvable body and an identification tag that is detectable by radiography. The dissolution of the patency capsule (Agile, Given Imaging) starts to occur after 30 hours. The patency capsule can be detected by radiography or by a portable radiofrequency scanner. When the patency capsule is successfully excreted or not detectable on radiography in the small bowel at 30 hours postingestion, it is usually safe to perform the diagnostic VCE. If the patency capsule location is not certain, it is possible to localize it with the assistance of contrast or air enhanced fluorography, or $\mathrm{CT} .{ }^{96}$ The rate of excretion of the patency capsule varies from $45 \%-88 \%,{ }^{78,88,97-99}$ depending upon patient selection. The main complication of the patency capsule is mild abdominal pain occurring in about $20 \%$ of patients. Clinically evident intestinal obstruction requiring surgical intervention has been reported in very few cases. ${ }^{78}$ This phenomenon may be explained by the lodging of the capsule in sites of obstruction not easily accessible by intestinal fluids necessary for the dissolution of the lactose in the patency capsule. ${ }^{100}$ The rate of uneventful completion of the VCE examination after successful excretion of the patency capsule approximates $100 \%{ }^{78}$ In cases of an unsuccessful patency capsule procedure, the small bowel should be investigated by cross-sectional imaging such as CT or MRE ${ }^{101}$ or by enteroscopy or surgery in cases of high clinical probability of a tumor, or when an inevitable need for tissue diagnosis arises. The main indications for administration of a patency capsule before ingestion of diagnostic VCE are listed in Table 2.

\section{Future directions}

Several important developments in the field of capsule endoscopy are anticipated in the near future. The most important and already used in clinical practice is the colon capsule. This device includes two cameras and records two different sets of images. The colonic capsule was compared with colonoscopy with promising results, with the second generation capsule reaching sensitivity of $88 \%$ for detection of polyps $>6 \mathrm{~mm}$ in comparison to colonoscopy. ${ }^{102,103}$

A capsule device aimed at evaluation of esophageal pathology (primarily varices and Barrett's esophagus) was

Table 2 Main indications for use of the patency capsule before performing video capsule endoscopy

Established Crohn's disease

History suggestive of small bowel obstruction

Recent abdominal surgery

Suspected small bowel strictures

Suspected small bowel tumor 
previously introduced by Given Imaging. This device was compared to the standard esophagoscopy with good sensitivity and specificity and excellent tolerability. This device has not gained widespread use, mainly due to the overall safety and availability of upper endoscopy that also allows evaluation of the stomach and the duodenum. ${ }^{102}$

Development of an externally operated capsule has also been attempted. Recently, a capsule device containing magnets in one of the domes, allowing a "joystick"-like manipulation of the capsule in the stomach and the esophagus, was introduced by Given Imaging. ${ }^{104}$ An additional device that can be manipulated is an electrically propelled capsule. ${ }^{105}$ Additional technological features in development include tissue diagnosis capabilities such as brushing, cytology, fluid aspiration, biopsy, drug delivery, and therapeutic (coagulation) capabilities. ${ }^{106}$

\section{Conclusion}

VCE of the small bowel is the most useful diagnostic tool for the evaluation of small bowel pathologies. It provides very high quality images of the entire length of the small bowel and has an excellent safety and tolerability profile. In addition to the existing indications, new possible applications for the capsule endoscopy technology along with significant technological enhancements are emerging.

\section{Disclosure}

Dr Seidman has received consultant fees and is a member of the speaker bureau for Given Imaging. The authors report no other conflicts of interest in this work.

\section{References}

1. Iddan G, Meron G, Glukhovsky A, Swain P. Wireless capsule endoscopy. Nature. 2000;405(6785):417-417.

2. Nakamura T, Terano A. Capsule endoscopy: past, present, and future. J Gastroenterol. 2008;43(2):93-99.

3. Eliakim R. Video capsule endoscopy of the small bowel. Curr Opin Gastroenterol. 2008;24(2):159-163.

4. Hara AK, Leighton JA, Sharma VK, Heigh RI, Fleischer DE. Imaging of small bowel disease: comparison of capsule endoscopy, standard endoscopy, barium examination, and CT. Radiographics. 2005;25(3):697-711.

5. Solem CA, Loftus EV Jr, Fletcher JG, et al. Small-bowel imaging in Crohn's disease: a prospective, blinded, 4-way comparison trial. Gastrointest Endosc. 2008;68(2):255-266.

6. Voderholzer WA, Ortner M, Rogalla P, Beinholzl J, Lochs H. Diagnostic yield of wireless capsule enteroscopy in comparison with computed tomography enteroclysis. Endoscopy. 2003;35(12):1009-1014.

7. Bourreille A, Ignjatovic A, Aabakken L, et al; World Organisation of Digestive Endoscopy (OMED) and the European Crohn's and Colitis Organisation (ECCO). Role of small-bowel endoscopy in the management of patients with inflammatory bowel disease: an international OMEDECCO consensus. Endoscopy. 2009;41(7):618-637.

8. Eliakim R. Video capsule endoscopy of the small bowel. Curr Opin Gastroenterol. 2010;26(2):129-133.
9. Ninomiya K, Yao K, Matsui T, et al. Effectiveness of Magnesium Citrate as Preparation for Capsule Endoscopy: A Randomized, Prospective, Open-Label, Inter-Group Trial. Digestion. 2012;86(1):27-33.

10. Kakugawa Y, Saito Y, Saito S, et al. New reduced volume preparation regimen in colon capsule endoscopy. World J Gastroenterol. 2012;18(17):2092-2098.

11. Ito T, Ohata K, Ono A, et al. Prospective controlled study on the effects of polyethylene glycol in capsule endoscopy. World J Gastroenterol. 2012;18(15):1789-1792.

12. Pons Beltran V, Gonzalez Suarez B, Gonzalez Asanza C, et al. Evaluation of different bowel preparations for small bowel capsule endoscopy: a prospective, randomized, controlled study. Dig Dis Sci. 2011;56(10):2900-2905.

13. Park SC, Keum B, Seo YS, et al. Effect of bowel preparation with polyethylene glycol on quality of capsule endoscopy. Dig Dis Sci. 2011;56(6):1769-1775.

14. Wi JH, Moon JS, Choi MG, et al; Korea Gut Image Group. Bowel preparation for capsule endoscopy: a prospective randomized multicenter study. Gut Liver. 2009;3(3):180-185.

15. Kantianis A, Karagiannis S, Liatsos C, et al. Comparison of two schemes of small bowel preparation for capsule endoscopy with polyethylene glycol: a prospective, randomized single-blind study. Eur J Gastroenterol Hepat. 2009;21(10):1140-1144.

16. Gerson LB. Preparation before capsule endoscopy: the value of the purge. Gastroenterology. 2009;137(3):1166-1168.

17. Niv Y. Efficiency of bowel preparation for capsule endoscopy examination: a meta-analysis. World J Gastroenterol. 2008;14(9):1313-1317.

18. Rokkas T, Papaxoinis K, Triantafyllou K, Pistiolas D, Ladas SD. Does purgative preparation influence the diagnostic yield of small bowel video capsule endoscopy? A meta-analysis. Am J Gastroenterol. 2009;104(1):219-227.

19. Eliakim R. Video capsule endoscopy of the small bowel. Curr Opin Gastroenterol. 2013;29(2):133-139.

20. Sidhu R, Sanders DS, Morris AJ, McAlindon ME. Guidelines on small bowel enteroscopy and capsule endoscopy in adults. Gut. 2008;57(1): 125-136.

21. Adler DG, Knipschield M, Gostout C. A prospective comparison of capsule endoscopy and push enteroscopy in patients with GI bleeding of obscure origin. Gastrointest Endosc. 2004;59(4):492-498.

22. Hartmann D, Schilling D, Bolz G, et al. Capsule endoscopy versus push enteroscopy in patients with occult gastrointestinal bleeding. Z Gastroenterol. 2003;41(5):377-382.

23. Mylonaki M, Fritscher-Ravens A, Swain P. Wireless capsule endoscopy: a comparison with push enteroscopy in patients with gastroscopy and colonoscopy negative gastrointestinal bleeding. Gut. 2003;52(8): $1122-1126$.

24. Ell C, May A, Nachbar L, et al. Push-and-pull enteroscopy in the small bowel using the double-balloon technique: Results of a prospective European Multicenter study. Endoscopy. 2005;37(7):613-616.

25. Triester SL, Leighton JA, Leontiadis GI, et al. A meta-analysis of the yield of capsule endoscopy compared to other diagnostic modalities in patients with obscure gastrointestinal bleeding. Am J Gastroenterol. 2005;100(11):2407-2418.

26. Pasha SF, Leighton JA, Das A, et al. Double-balloon enteroscopy and capsule endoscopy have comparable diagnostic yield in small-bowel disease: A meta-analysis. Clin Gastroenterol Hepatol. 2008;6(6):671-676.

27. Marmo R, Rotondano G, Piscopo R, Bianco MA, Cipolletta L. Metaanalysis: capsule enteroscopy vs conventional modalities in diagnosis of small bowel diseases. Aliment Pharmacol Ther. 2005;22(7):595-604.

28. Marmo R, Rotondano G, Piscopo R, et al. Capsule endoscopy versus enteroclysis in the detection of small-bowel involvement in Crohn's disease: A prospective trial. Clin Gastroenterol Hepatol. 2005;3(8): 772-776.

29. Eliakim R, Suissa A, Yassin K, Katz D, Fischer D. Wireless capsule video endoscopy compared to barium follow-through and computerised tomography in patients with suspected Crohn's disease - final report. Dig Liver Dis. 2004;36(8):519-522. 
30. Macdonald J, Porter V, McNamara D. Negative capsule endoscopy in patients with obscure GI bleeding predicts low rebleeding rates. Gastrointest Endosc. 2008;68(6):1122-1127.

31. Bar-Meir S, Eliakim R, Nadler M, et al. Second capsule endoscopy for patients with severe iron deficiency anemia. Gastrointest Endosc. 2004;60(5):711-713.

32. Jones BH, Fleischer DE, Sharma VK, et al. Yield of repeat wireless video capsule endoscopy in patients with obscure gastrointestinal bleeding. Am J Gastroenterol. 2005;100(5):1058-1064.

33. Liu K, Kaffes AJ. Review article: the diagnosis and investigation of obscure gastrointestinal bleeding. Aliment Pharmacol Ther. 2011;34(4):416-423.

34. Bresci G, Parisi G, Bertoni M, Tumino E, Capria A. The role of video capsule endoscopy for evaluating obscure gastrointestinal bleeding: usefulness of early use. J Gastroenterol. 2005;40(3):256-259.

35. Stange EF, Travis SPL, Vermeire S, et al; European Crohn's and Colitis Organisation. European evidence based consensus on the diagnosis and management of Crohn's disease: definitions and diagnosis. Gut. 2006; 55 Suppl 1:i1-i15.

36. Molinie F, Gower-Rousseau C, Yzet T, et al. Opposite evolution in incidence of Crohn's disease and ulcerative colitis in Northern France (1988-1999). Gut. 2004;53(6):843-848.

37. Silverberg MS, Satsangi J, Ahmad T, et al. Toward an integrated clinical, molecular and serological classification of inflammatory bowel disease: Report of a Working Party of the 2005 Montreal World Congress of Gastroenterology. Can J Gastroenterol. 2005;19 Suppl A: $5-36$.

38. Bar-Meir S. Review article: capsule endoscopy - are all small intestinal lesions Crohn's disease? Aliment Pharmacol Ther. 2006;24 Suppl 3: $19-21$.

39. Graham DY, Opekun AR, Willingham FF, Qureshi WA. Visible smallintestinal mucosal injury in chronic NSAID users. Clin Gastroenterol Hepatol. 2005;3(1):55-59.

40. Maiden L, Thjoleifsson B, Seigal A, et al. Long-term effects of nonsteroidal anti-inflammatory drugs and cyclooxygenase- 2 selective agents on the small bowel: A cross-sectional capsule enteroscopy study. Clin Gastroenterol Hepatol. 2007;5(9):1040-1045.

41. Gralnek IM, Defranchis R, Seidman E, Leighton JA, Legnani P, Lewis BS. Development of a capsule endoscopy scoring index for small bowel mucosal inflammatory change. Aliment Pharmacol Ther. 2008;27(2):146-154

42. Niv Y, Ilani S, Levi Z, et al. Validation of the Capsule Endoscopy Crohn's Disease Activity Index (CECDAI or Niv score): a multicenter prospective study. Endoscopy. 2012;44(1):21-26.

43. de Melo SW Jr, Di Palma JA. The role of capsule endoscopy in evaluating inflammatory bowel disease. Gastroenterol Clin North Am. 2012;41(2):315-323.

44. Triester SL, Leighton JA, Leontiadis GI, et al. A meta-analysis of the yield of capsule endoscopy compared to other diagnostic modalities in patients with non-stricturing small bowel Crohn's disease. Am J Gastroenterol. 2006;101(5):954-964.

45. Dionisio PM, Gurudu SR, Leighton JA, et al. Capsule endoscopy has a significantly higher diagnostic yield in patients with suspected and established small-bowel Crohn's disease: a meta-analysis. Am J Gastroenterol. 2010;105(6):1240-1248.

46. Jensen MD, Nathan T, Rafaelsen SR, Kjeldsen J. Diagnostic accuracy of capsule endoscopy for small bowel Crohn's disease is superior to that of MR enterography or CT enterography. Clin Gastroenterol Hepatol. 2011;9(2):124-129.

47. Tillack C, Seiderer J, Brand S, et al. Correlation of magnetic resonance enteroclysis (MRE) and wireless capsule endoscopy (CE) in the diagnosis of small bowel lesions in Crohn's disease. Inflamm Bowel Dis. 2008;14(9):1219-1228.

48. Crook DW, Knuesel PR, Froehlich JM, et al. Comparison of magnetic resonance enterography and video capsule endoscopy in evaluating small bowel disease. Eur J Gastroenterol Hepatol. 2009;21(1): $54-65$.
49. Lazarev M, Huang C, Bitton A, et al. Relationship between proximal Crohn's disease location and disease behavior and surgery: a crosssectional study of the IBD Genetics Consortium. Am J Gastroenterol. 2013;108(1):106-112.

50. Beltran VP, Nos P, Bastida G, et al. Evaluation of postsurgical recurrence in Crohn's disease: a new indication for capsule endoscopy? Gastrointest Endosc. 2007;66(3):533-540.

51. Efthymiou A, Viazis N, Mantzaris G, et al. Does Clinical Response Correlate with Mucosal Healing in Patients with Crohn's Disease of the Small Bowel? A Prospective, Case-series Study Using Wireless Capsule Endoscopy. Inflamm Bowel Dis. 2008;14(11):1542-1547.

52. Rokkas T, Niv Y. The role of video capsule endoscopy in the diagnosis of celiac disease: a meta-analysis. Eur J Gastroenterol Hepatol. 2012;24(3):303-308.

53. Rondonotti E, Herrerias JM, Pennazio M, Caunedo A, MascarenhasSaraiva M, de Franchis R. Complications, limitations, and failures of capsule endoscopy: a review of 733 cases. Gastrointest Endosc. 2005;62(5):712-716.

54. Ciaccio EJ, Tennyson CA, Bhagat G, Lewis SK, Green PH. Quantitative estimates of motility from videocapsule endoscopy are useful to discern celiac patients from controls. Dig Dis Sci. 2012; 57(11):2936-2943,

55. Ciaccio EJ, Tennyson CA, Lewis SK, Krishnareddy S, Bhagat G, Green PH. Distinguishing patients with celiac disease by quantitative analysis of videocapsule endoscopy images. Comput Methods Programs Biomed. 2010;100(1):39-48.

56. Culliford A, Daly J, Diamond B, Rubin M, Green PHR. The value of wireless capsule endoscopy in patients with complicated celiac disease. Gastrointest Endosc. 2005;62(1):55-61.

57. Apostolopoulos P, Alexandrakis G, Giannakoulopoulou E, et al. M2A wireless capsule endoscopy for diagnosing ulcerative jejunoileitis complicating Celiac disease. Endoscopy. 2004;36(3):247-247.

58. Spada C, Riccioni ME, Urgesi R, Costamagna G. Capsule endoscopy in celiac disease. World J Gastroenterol. 2008;14(26):4146-4151.

59. Rondonotti E, Spada C, Cave D, et al. Video capsule enteroscopy in the diagnosis of celiac disease: a multicenter study. Am J Gastroenterol. 2007;102(8):1624-1631

60. Schwartz GD, Barkin JS. Small-bowel tumors detected by wireless capsule endoscopy. Dig Dis Sci. 2007;52(4):1026-1030.

61. Bailey AA, Debinski HS, Appleyard MN, et al. Diagnosis and outcome of small bowel tumors found by capsule endoscopy: A threecenter Australian experience. Am J Gastroenterol. 2006;101(10): 2237-2243.

62. Girelli CM, Porta P, Colombo E, Lesinigo E, Bernasconi G. Development of a novel index to discriminate bulge from mass on small-bowel capsule endoscopy. Gastrointest Endosc. 2011;74(5):1067-1074.

63. Barkay O, Moshkowitz M, Fireman Z, et al. Initial experience of videocapsule endoscopy for diagnosing small-bowel, tumors in patients with GI polyposis syndromes. Gastrointest Endosc. 2005;62(3):448-452.

64. Burke CA, Santisi J, Church J, Levinthal G. The utility of capsule endoscopy small bowel surveillance in patients with polyposis. Am J Gastroenterol. 2005;100(7):1498-1502.

65. Iaquinto G, Fornasarig M, Quaia M, et al. Capsule endoscopy is useful and safe for small-bowel surveillance in familial adenomatous polyposis. Gastrointest Endosc. 2008;67(1):61-67.

66. Mata A, Llach J, Castells A, et al. A prospective trial comparing wireless capsule endoscopy and barium contrast series for small-bowel surveillance in hereditary GI polyposis syndromes. Gastrointest Endosc. 2005;61(6):721-725.

67. Schulmann K, Hollerbach S, Kraus K, et al. Feasibility and diagnostic utility of video capsule endoscopy for the detection of small bowel polyps in patients with hereditary polyposis syndromes. Am J Gastroenterol. 2005;100(1):27-37.

68. Wong RF, Tuteja AK, Haslem DS, et al. Video capsule endoscopy compared with standard endoscopy for the evaluation of small-bowel polyps in persons with familial adenomatous polyposis (with video) Gastrointest Endosc. 2006;64(4):530-537. 
69. Bardan E, Nadler M, Chowers Y, Fidder H, Bar-Meir S. Capsule endoscopy for the evaluation of patients with chronic abdominal pain. Endoscopy. 2003;35(8):688-689.

70. Ohlsson B, Bengtsson M, Nielsen J, Toth E. A prospective evaluation of the diagnostic value of video capsule endoscopy in patients initially classified as irritable bowel syndrome. Eur J Intern Med. 2009;20(1):48-52.

71. Ersoy O, Akin E, Demirezer A, et al. Evaluation of primary intestinal lymphangiectasia by capsule endoscopy. Endoscopy. 2013;45 Suppl 2: E61-E62.

72. Endo H, Hosono K, Inamori M, et al. Capsule endoscopic evaluation of eosinophilic enteritis before and after treatment. Digestion. 2011; 83(1-2):134-135.

73. Pasha SF, Leighton JA. Endoscopic techniques for small bowel imaging. Radiol Clin North Am. 2013;51(1):177-187.

74. Malagelada C, De Iorio F, Azpiroz F, et al. New insight into intestinal motor function via noninvasive endoluminal image analysis. Gastroenterology. 2008;135(4):1155-1162.

75. Saad RJ, Hasler WL. A technical review and clinical assessment of the wireless motility capsule. Gastroenterol Hepatol. 2011;7(12): 795-804.

76. Cave D, Legnani P, de Franchis R, Lewis BS. ICCE consensus for capsule retention. Endoscopy. 2005;37(10):1065-1067.

77. Sidhu R, Sanders DS, McAlindon ME, Kapur K. Capsule endoscopy for the evaluation of nonsteroidal anti-inflammatory drug-induced enteropathy: United Kingdom pilot data. Gastrointest Endosc. 2006;64(6):1035.

78. Caunedo-Alvarez A, Romero-Vazquez J, Herrerias-Gutierrez JM. Patency and Agile capsules. World J Gastroenterol. 2008;14(34): 5269-5273.

79. Goldstein JL, Eisen GM, Lewis B, Gralnek IM, Zlotnick S, Fort JG; Investigators. Video capsule endoscopy to prospectively assess small bowel injury with celecoxib, naproxen plus omeprazole, and placebo. Clin Gastroenterol Hepatol. 2005;3(2):133-141.

80. Pennazio M, Santucci R, Rondonotti E, et al. Outcome of patients with obscure gastrointestinal bleeding after capsule endoscopy: Report of 100 consecutive cases. Gastroenterology. 2004;126(3):643-653.

81. Sears DM, Avots-Avotins A, Culp K, Gavin MW. Frequency and clinical outcome of capsule retention during capsule endoscopy for GI bleeding of obscure origin. Gastrointest Endosc. 2004;60(5):822-827.

82. Fireman Z, Mahajna E, Broide E, et al. Diagnosing small bowel Crohn's disease with wireless capsule endoscopy. Gut. 2003;52(3):390-392.

83. Eliakim R, Fischer D, Suissa A, et al. Wireless capsule video endoscopy is a superior diagnostic tool in comparison to barium follow-through and computerized tomography in patients with suspected Crohn's disease. Eur J Gastroenterol Hepatol. 2003;15(4):363-367.

84. Herrerias JM, Caunedo A, Rodriguez-Tellez M, Pellicer F, Herrerias JM Jr. Capsule endoscopy in patients with suspected Crohn's disease and negative endoscopy. Endoscopy. 2003;35(7):564-568.

85. Cheifetz AS, Kornbluth AA, Legnani P, et al. The risk of retention of the capsule endoscope in patients with known or suspected Crohn's disease. Am J Gastroenterol. 2006;101(10):2218-2222.

86. Mow WS, Lo SK, Targan SR, et al. Initial experience with wireless capsule enteroscopy in the diagnosis and management of inflammatory bowel disease. Clin Gastroenterol Hepatol. 2004;2(1):31-40.

87. Cheifetz AS, Lewis BS. Capsule endoscopy retention: Is it a complication? J Clin Gastroenterol. 2006;40(8):688-691.

88. Boivin ML, Lochs H, Voderholzer WA. Does passage of a patency capsule indicate small-bowel patency? A prospective clinical trial? Endoscopy. 2005;37(9):808-815.

89. Li F, Gurudu SR, De Petris G, et al. Retention of the capsule endoscope: a single-center experience of 1000 capsule endoscopy procedures. Gastrointest Endosc. 2008;68(1):174-180.

90. Palmer JS, Marenah K, El Madani F, Jain K, Gupta S. Small bowel perforation following capsule endoscopy: a case report. Ann $R$ Coll Surg Engl. 2011;93(6):e69-e70.

91. Bandorski D, Irnich W, Bruck M, Beyer N, Kramer W, Jakobs R. Capsule endoscopy and cardiac pacemakers: investigation for possible interference. Endoscopy. 2008;40(1):36-39.
92. Bandorski D, Lotterer E, Hartmann D, et al. Capsule endoscopy in patients with cardiac pacemakers and implantable cardioverterdefibrillators - a retrospective multicenter investigation. J Gastrointestin Liver Dis. 2011;20(1):33-37.

93. Payeras G, Piqueras J, Moreno VJ, Cabrera A, Menendez D, Jimenez R. Effects of capsule endoscopy on cardiac pacemakers. Endoscopy. 2005;37(12):1181-1185.

94. Dirks MH, Costea F, Seidman EG. Successful videocapsule endoscopy in patients with an abdominal cardiac pacemaker. Endoscopy. 2008;40(1):73-75.

95. Waterman M, Eliakim R. Capsule enteroscopy of the small intestine. Abdom Imaging. 2009;34(4):452-458.

96. Postgate AJ, Burling D, Gupta A, Fitzpatrick A, Fraser C. Safety, reliability and limitations of the given patency capsule in patients at risk of capsule retention: A 3-year technical review. Dig Dis Sci. 2008;53(10):2732-2738.

97. Delvaux M, Ben Soussan E, Laurent V, Lerebours E, Gay G. Clinical evaluation of the use of the M2A patency capsule system before a capsule endoscopy procedure, in patients with known or suspected intestinal stenosis. Endoscopy. 2005;37(9):801-807.

98. Signorelli C, Rondonotti E, Villa F, et al. Use of the Given Patency System for the screening of patients at high risk for capsule retention. Dig Liver Dis. 2006;38(5):326-330.

99. Spada C, Shah SK, Riccioni ME, et al. Video capsule endoscopy in patients with known or suspected small bowel stricture previously tested with the dissolving patency capsule. J Clin Gastroenterol. 2007;41(6):576-582.

100. Gay G, Delvaux M, Fassler I. Outcome of capsule endoscopy in determining indication and route for push-and-pull enteroscopy. Endoscopy. 2006;38(1):49-58

101. Fork FT, Karlsson N, Kadhem S, Ohlsson B. Small bowel enteroclysis with magnetic resonance imaging and computed tomography in patients with failed and uncertain passage of a patency capsule. $B M C$ Med Imaging. 2012;12:3.

102. Ladas SD, Triantafyllou K, Spada C, et al; ESGE Clinical Guidelines Committee. European Society of Gastrointestinal Endoscopy (ESGE): recommendations (2009) on clinical use of video capsule endoscopy to investigate small-bowel, esophageal and colonic diseases. Endoscopy. 2010;42(3):220-227.

103. Eliakim R, Yassin K, Niv Y, et al. Prospective multicenter performance evaluation of the second-generation colon capsule compared with colonoscopy. Endoscopy. 2009;41(12):1026-1031.

104. Keller J, Fibbe C, Rosien U, Layer P. Recent advances in capsule endoscopy: development of maneuverable capsules. Expert Rev Gastroenterol Hepatol. 2012;6(5):561-566.

105. Woo SH, Kim TW, Mohy-Ud-Din Z, Park IY, Cho JH. Small intestinal model for electrically propelled capsule endoscopy. Biomed Eng Online. 2011;10:108.

106. Swain P. The future of wireless capsule endoscopy. World $J$ Gastroenterol. 2008;14(26):4142-4145.

107. Lecleire S, Iwanicki-Caron I, Di-Fiore A, et al. Yield and impact of emergency capsule enteroscopy in severe obscure-overt gastrointestinal bleeding. Endoscopy. 2012;44(4):337-342.

108. Mussetto A, Fuccio L, Dari S, et al. MiroCam capsule for obscure gastrointestinal bleeding: a prospective, single centre experience. Dig Liver Dis. 2013;45(2):124-128.

109. Parikh DA, Mittal M, Leung FW, Mann SK. Improved diagnostic yield with severity of bleeding. J Dig Dis. 2011;12(5):357-363.

110. Yamada A, Watabe H, Kobayashi Y, Yamaji Y, Yoshida H, Koike K. Timing of capsule endoscopy influences the diagnosis and outcome in obscure-overt gastrointestinal bleeding. Hepatogastroenterology. 2012;59(115):676-679.

111. Tong J, Svarta S, Ou G, Kwok R, Law J, Enns R. Diagnostic yield of capsule endoscopy in the setting of iron deficiency anemia without evidence of gastrointestinal bleeding. Can J Gastroenterol. 2012;26(10):687-690.

112. Fry LC, Carey EJ, Shiff AD, et al. The yield of capsule endoscopy in patients with abdominal pain or diarrhea. Endoscopy. 2006;38(5):498-502. 
Clinical and Experimental Gastroenterology

Dovepress

\section{Publish your work in this journal}

Clinical and Experimental Gastroenterology is an international, peerreviewed, open access journal, publishing all aspects of gastroenterology in the clinic and laboratory, including: Pathology, pathophysiology of gastrointestinal disease; Investigation and treatment of gastointestinal disease; Pharmacology of drugs used in the alimentary tract;

Immunology/genetics/genomics related to gastrointestinal disease. This journal is indexed on CAS. The manuscript management system is completely online and includes a very quick and fair peer-review system. Visit http://www.dovepress.com/testimonials.php to read real quotes from published authors.

Submit your manuscript here: http://www.dovepress.com/clinical-and-experimental-gastroenterology-journal 